\title{
PropagaCIÓN IN VITRO DE ESPECIES DE ECHINOCEREUS, Escontria, Mammillaria, Melocactus y POLASKIA (CACTACEAE)
}

\author{
José Luis Retes-Pruneda, María de Lourdes Valadez-Aguilar, Martha \\ Evelia Pérez-Reyes y Eugenio Pérez-Molphe-Balch' \\ Departamento de Química, Centro de Ciencias Básicas, Universidad Autónoma de Aguascalientes, \\ Av. Universidad 940, Aguascalientes, 20100, Ags., México. \\ 1 Autor para la correspondencia; correo-e: eperezmb@correo.uaa.mx; \\ tel: (449)910-84-20; fax: (449)910-84-01
}

\begin{abstract}
Resumen: Se desarrollaron sistemas para la propagación in vitro a través de la activación de areolas para Echinocereus knippe lianus, Echinocereus schmollii, Mammillaria carmenae, M. carmenae fo. rubrisprina, M. herrerae, M. theresae, Melocactus cur vispinus, Escontria chiotilla y Polaskia chichipe. Como fuente de explantes se usaron plántulas germinadas in vitro. Se logró la formación de brotes múltiples a partir de las areolas en medio basal MS con 3\% de sacarosa, $10 \mathrm{~g} \mathrm{~L}^{-1}$ de agar y 6-bencilaminopurina (BA) o 6-( , -dimetilalilamino)purina (2iP). Las eficiencias más altas fluctuaron entre 6.0 brotes por explante en $M$. car menae fo. rubrisprina, hasta 13.5 brotes por explante en Echinocereus schmollii. El enraizamiento de los brotes generados in vitro se logró en medio basal MS, o en medio MS basal complementado con ácido indolacético, ácido indolbutírico o carbón activado. Finalmente, 49-98\% de estas plántulas sobrevivieron en suelo.
\end{abstract}

Palabras clave: activación de areolas, cactáceas, citocininas, cultivo in vitro, plantas amenazadas.

\begin{abstract}
In vitro propagation systems by means of areole activation were developed for Echinocereus knippelianus, Echinocereus schmollii, Mammillaria carmenae, M. carmenae fo. rubrisprina, M. herrerae, M. theresae, Melocactus curvispi nus, Escontria chiotilla and Polaskia chichipe. In vitro germinated seedlings were used as source of explants. Multiple shoot formation from areoles was achieved on MS basal medium supplemented with $3 \%$ sucrose, $10 \mathrm{~g} \mathrm{~L}^{-1}$ agar and 6-benzylaminopurine (BA) or 6-( , -dimethylallylamino)purine (2iP). Efficiencies ranged from 6.0 shoots per explant in M. carmenae fo. rubrisprina to 13.5 shoots per explant in Echinocereus schmollii. Rooting of the in vitro generated shoots was achieved in MS basal medium, or MS basal medium supplemented with indoleacetic acid, indolebutyric acid or activated charcoal. Finally, 49-98\% of these plants survived.
\end{abstract}

Key words: areole activation, cacti, cytokinins, in vitro culture, threatened species.

$\mathbf{M}$ éxico cuenta con alrededor de 660 especies de cactáceas distribuidas a lo largo de todo su territorio, $78 \%$ de las cuales (517) son endémicas (Ortega-Baes y GodínezÁlvarez, 2006). Estas plantas son de especial interés, ya que han sido usadas tradicionalmente como fuente de alimentos, forrajes, materiales para la construcción y medicamentos, y cada vez cobran más importancia como ornamentales (Bravo-Hollis y Sánchez-Mejorada, 1991). Desafortunadamente, hoy en día 217 especies de cactáceas mexicanas se consideran amenazadas y algunas están en peligro inminente de extinción (SEMARNAT, 2002). Esto se debe al efecto adverso de las actividades humanas, entre las que destacan la sobreexplotación de las poblaciones silvestres, la destrucción de su hábitat y el saqueo provocado por la colecta ilegal de ejemplares para su venta. Por otro lado, los cactus poseen características ecológicas como sus distribuciones geográficas restringidas, ciclos de vida largos y tasas de crecimiento reducidas, que los hacen especialmente sensibles a las perturbaciones ambientales (Hernández y Godínez-A., 1994). Además, sus tasas de reproducción son 
también muy bajas, ya que muchas especies no se reproducen vegetativamente, y la producción de semillas es escasa debido a fenómenos como la autoincompatibilidad. Por su parte, las plántulas son muy susceptibles a las pudriciones causadas por hongos, a la depredación y a los factores ambientales adversos, lo que hace que sólo una proporción muy baja llegue al estado adulto. Esto ocasiona que el reclutamiento de nuevos individuos en las poblaciones sea mínimo. Por ejemplo, se reporta que sólo $0.001 \%$ de las semillas producidas en una población de Carnegiea gigan tea sobrevivieron a la depredación (Steenbergh y Lowe, 1969), mientras que en una población de Ferocactus acanthodes sólo se reclutaron 30 nuevos individuos por ha en un período de 18 años (Jordan y Nobel, 1981).

La aplicación de métodos biotecnológicos, como la multiplicación in vitro, puede contribuir a aliviar esta situación al hacer posible la propagación rápida y masiva de las cactáceas. Se sabe además que estas condiciones de cultivo en medios artificiales aceleran significativamente el crecimiento de estas plantas, confiriendo así una ventaja adicional a esta metodología (Malda et al., 1999). Sin embargo, también se ha encontrado que cada especie responde de manera diferente a las condiciones y a los reguladores del crecimiento usados en el cultivo in vitro, por lo que es necesario trabajar con cada una de ellas para encontrar el protocolo más adecuado y conocer su eficiencia de propagación bajo estos sistemas (Hubstenberger et al., 1992). Uno de los métodos más usados para la propagación in vitro de cactáceas es la generación de brotes a través de la activación de areolas, estructuras que contienen las yemas axilares. Este método resulta muy adecuado para la conservación de las características genotípicas de las especies, ya que no genera variación somaclonal, como sí lo pueden hacer los métodos indirectos de regeneración, cuya primera etapa es la producción de tejido calloso (Machado y Prioli, 1996). La activación de areolas se logra mediante la adición de citocininas al medio de cultivo, siendo las más usadas la 6-bencilaminopurina o benciladenina (BA), la 6(, -dimetilalilamino)purina o 2-isopenteniladenina (2iP) y la furfurilaminopurina o cinetina (Hubstenberger et al., 1992).

A pesar del gran número de especies mexicanas de cactáceas de importancia ecológica, o con un uso potencial interesante, sólo se han establecido protocolos para la multiplicación in vitro de una fracción muy pequeña de ellas. Algunos ejemplos de estos sistemas son los reportados para Mammillaria san-angelensis (Martínez-Vázquez y Rubluo, 1989), Aztekium ritteri (Rodríguez-Garay y Rubluo, 1992), Mammillaria candida (Elias-Rocha et al., 1998), Coryphantha minima y Obregonia denegrii (Malda et al., 1999), Turbinicarpus laui (Mata-Rosas et al., 2001), Pelecyphora aselliformis y $P$. strobiliformis (PérezMolphe-Balch y Dávila-Figueroa, 2002), Carnegiea gigan tea, Pachycereus pringlei y Stenocereus thurberi (Pérez-
Molphe-Balch et al., 2002), Ariocarpus kotschoubeyanus (Moebius-Goldammer et al., 2003) y otras ocho especies y subespecies de Turbinicarpus (Dávila-Figueroa et al., 2005). En este trabajo se reportan métodos eficientes para la propagación in vitro de las cactáceas Echinocereus knip pelianus Liebm., Echinocereus schmollii (Weing.) N.P.Taylor, Mammillaria carmenae Castañeda, M. carme nae fo. rubrisprina, $M$. herrerae Werdermann, $M$. theresae Cutak, Melocactus curvispinus Pfeiff., Escontria chiotilla (F.A.C.Weber) Rose y Polaskia chichipe (Rol.-Goss.) Backeb. Las seis primeras están catalogadas como amenazadas o en peligro de extinción de acuerdo con la Norma Oficial Mexicana (SEMARNAT, 2002), mientras que las dos últimas son de interés debido a la producción de frutos muy ap reciados por los pobladores de las regiones que habitan, lo que las hace candidatas para una explotación más intensiva.

\section{Materiales y métodos}

El material vegetal que se utilizó en este trabajo fueron plántulas obtenidas in vitro de las especies Echinocereus knippelianus, Echinocereus schmollii, Escontria chiotilla, Mammillaria carmenae, M. carmenae fo. rubrisprina, $M$. herrerae, M. theresae, Melocactus curvispinus y Polaskia chichipe. Estas plántulas se generaron a partir de la germinación de semillas en condiciones axénicas. Para esto, las semillas se lavaron cinco veces con agua corriente con $0.1 \%$ de Extran (Merck), luego se colocaron por 1 min en etanol al $70 \%$ y finalmente se desinfectaron por 25 min en blanqueador comercial (Cloralex) al 15\% (v/v). Después de la desinfección, las semillas se llevaron a la campana de flujo laminar donde se enjuagaron cuatro veces con agua destilada estéril y se inocularon en condiciones asépticas en frascos con $30 \mathrm{~mL}$ de medio MS (Murashige y Skoog, 1962) al 50\%, pH 5.7 y solidificado con $1 \%$ de agar. Los frascos de cultivo se sellaron con película autoadherible de PVC (Vitafilm) y fueron incubados bajo condiciones controladas. Cuando las plántulas alcanzaron 6-10 $\mathrm{mm}$ de altura (3-6 meses, dependiendo de la especie) se utilizaron como fuente de explantes para los experimentos de proliferación in vitro a través de la activación de areolas. Para esto, se eliminó su parte basal y se cortó su porción apical. El tejido restante se cortó transversalmente para formar rebanadas de aproximadamente $4 \mathrm{~mm}$ de grueso. Tanto los ápices como los segmentos transversales fueron inoculados en medio MS, $3 \%$ de sacarosa, adicionado con tres concentraciones de BA $\left(0.5,1.0\right.$ y $\left.2.0 \mathrm{mg} \mathrm{L}^{-1}\right)$ y tres de 2 -isopentiladenina (2iP) $\left(1.0,3.0\right.$ y $\left.5.0 \mathrm{mg} \mathrm{L}^{-1}\right), \mathrm{pH} 5.7,1 \%$ de agar. El testigo usado fue medio basal (MS sin citocininas). Se inocularon de 15 a 30 explantes por tratamiento, dependiendo de la disponibilidad de material de cada especie. Todos los cultivos fueron incubados bajo luz continua (54 mol $\left.\mathrm{m}^{-2} \mathrm{~s}^{-1}\right)$ a $25 \pm 2^{\circ} \mathrm{C}$. Los experimentos completos se 
realizaron al menos dos veces. Para las réplicas se utilizó material vegetal generado en los experimentos previos. Los resultados se registraron a los 45-60 días de incubación, dependiendo de la tasa de crecimiento de cada especie. La respuesta evaluada fue el número de brotes generados por explante en los diferentes tratamientos. Con el fin de analizar el efecto de los tratamientos probados, los datos se analizaron mediante ANDEVA y la comparación entre las medias se hizo mediante la prueba de Tukey Kramer ( = 0.05). Para el enraizamiento, los brotes generados en los tratamientos antes descritos se individualizaron y transfirieron a medio MS basal con cuatro tratamientos diseñados para estimular el enraizamiento de los brotes: (a) MS basal; (b) MS con $2 \mathrm{~g} \mathrm{~L}^{-1}$ de carbón activado; (c) MS con $0.5 \mathrm{mg}$ $\mathrm{L}^{-1}$ de ácido indolbutírico (AIB); y (d) medio MS con 0.5 $\mathrm{mg} \mathrm{L}^{-1}$ ácido indolacético (AIA). Estos tratamientos se mantuvieron por 30-45 días hasta que se formó un sistema radical vigoroso; entonces se realizó el proceso de adaptación a suelo. Para esto, se aflojó un poco la tapa del recipiente y así se dejó por siete días, después se retiraron las plantas del medio de cultivo, el cual se eliminó por completo de la raíz con ayuda de agua corriente, y se sembraron en macetas con una mezcla de tierra comercial para macetas y arena (1:1) previamente humedecida. Las macetas se colocaron en bolsas de plástico; una vez cerradas se mantuvieron en una cámara bioclimática a $26 \pm 2{ }^{\circ} \mathrm{C}$ y un fotoperíodo de $16 \mathrm{~h}$ luz, $8 \mathrm{~h}$ de oscuridad. A los dos o tres días se comenzó a abrir la bolsa, la cual se retiró por completo a los 15 días. Las macetas se mantuvieron por 30 días más en la cámara bioclimática y luego se llevaron al invernadero, en donde se determinó la tasa de supervivencia a los 90 días. Se consideró como sobrevivientes sólo a aquellas plantas que habían reiniciado su crecimiento ya en suelo.

\section{Resultados y discusión}

El método utilizado para la desinfección de las semillas fue satisfactorio, ya que el porcentaje de contaminación en todas las especies fue inferior a $15 \%$. En cuanto a la tasa de germinación, ésta fue variable entre las especies estudiadas, observándose un intervalo desde $43 \%$ en Echinocereus schmollii, hasta $98 \%$ en Polaskia chichipe. Para la mayoría de las especies se obtuvieron plántulas de 6 a $10 \mathrm{~mm}$ con una morfología normal a los tres meses de iniciado el cultivo. Sólo en el caso de las pertenecientes al género Mammillaria se requirió del doble de tiempo para que las plántulas alcanzaran esta talla. Además, 20\% de las plántulas obtenidas en este género mostraron una morfología anormal, hiperhidratándose y generando tejido calloso. Estas plántulas no fueron utilizadas para los experimentos subsecuentes.

Las plántulas axénicas obtenidas in vitro se utilizaron como fuente de explantes para los experimentos de propagación a través de la activación de areolas. En éstos, se generaron brotes en todas las especies tanto con BA, como con $2 \mathrm{iP}$ (cuadro 1; figura 1). Sin embargo, la eficiencia varió entre los tratamientos y entre las especies. En ninguna especie se observó la aparición de brotes en el medio testigo (sin citocininas). Algunos de los ápices cultivados en este medio crecieron y generaron raíces. La mejor respuesta se obtuvo en Echinocereus schmollii, en donde el tratamiento con $2 \mathrm{mg} \mathrm{L}^{-1}$ de BA generó un promedio de 13.5 brotes por explante. El resto de las especies generaron entre 6.0 y 11.8 brotes por explante en sus mejores tratamientos. Usando sistemas de regeneración similares en otras cactáceas se han reportado eficiencias de 14 brotes por explante en Mediocactus coccineus (Infante, 1992), 13.7 y 12.8 brotes por explante en Pelecyphora aselliformis y $P$. strobiliformis, respectivamente (Pérez-Molphe-Balch y Dávila-Figueroa, 2002) y 13.8 brotes por explante en Opuntia ficus-indica (García-Saucedo et al., 2005).

Las especies Echinocereus knippelianus, Echinocereus schmollii, Mammillaria carmenae, M. herrerae, Escontria chiotilla y Polaskia chichipe respondieron significativamente mejor a los tratamientos con BA, mientras que $M$. theresae y Melocactus curvispinus lo hicieron a los tratamientos con 2iP. Sólo en M. carmenae fo. rubrisprina no hubo diferencias significativas entre tratamientos con BA y 2iP, siendo ambas citocininas igualmente eficientes para generar brotes. Cabe mencionar que estas dos citocininas son las más empleadas para la propagación de cactáceas a través de la activación de areolas (Hubstenberger et al.,

Cuadro 1. Generación de brotes a través de la activación de areolas en explantes de nueve cactáceas tratados con dos citocininas. Resultados a los 45-60 días de iniciados los cultivos.

\begin{tabular}{|c|c|c|c|}
\hline Especie & BA mg L-1 & $2 \mathrm{iP} \mathrm{mg} \mathrm{L^{-1 }}$ & $\begin{array}{l}\text { Brotes por explante } \\
\quad(\text { media } \pm \mathrm{EE})^{*}\end{array}$ \\
\hline \multirow{7}{*}{ Echinocereus knippelianus } & - & - & $0.0 \pm 0.00 \mathrm{e}$ \\
\hline & 0.5 & 一 & $3.6 \pm 0.31 \mathrm{c}$ \\
\hline & 1.0 & - & $5.5 \pm 0.44 b$ \\
\hline & 2.0 & 一 & $8.9 \pm 0.35 a$ \\
\hline & - & 1.0 & $1.8 \pm 0.11 \mathrm{~d}$ \\
\hline & - & 3.0 & $3.0 \pm 0.16 \mathrm{c}$ \\
\hline & - & 5.0 & $3.5 \pm 0.18 \mathrm{c}$ \\
\hline
\end{tabular}


José Luis Retes-PRUNEDA ET AL.

Cuadro 1. Continuación

\begin{tabular}{|c|c|c|c|}
\hline Especie & $\mathrm{BA} \mathrm{mg} \mathrm{L}^{-1}$ & $2 \mathrm{iP} \mathrm{mg} \mathrm{L}{ }^{-1}$ & $\begin{array}{l}\text { Brotes por explante } \\
\quad(\text { media } \pm \mathrm{EE})^{*}\end{array}$ \\
\hline \multirow[t]{7}{*}{ Echinocereus schmollii } & - & - & $0.0 \pm 0.00 \mathrm{~g}$ \\
\hline & 0.5 & - & $2.8 \pm 0.16 \mathrm{f}$ \\
\hline & 1.0 & - & $9.3 \pm 0.36 \mathrm{~b}$ \\
\hline & 2.0 & - & $13.5 \pm 0.60 \mathrm{a}$ \\
\hline & - & 1.0 & $4.2 \pm 0.22 \mathrm{e}$ \\
\hline & -- & 3.0 & $6.2 \pm 0.30 \mathrm{~d}$ \\
\hline & - & 5.0 & $7.8 \pm 0.38 \mathrm{c}$ \\
\hline \multirow[t]{7}{*}{ Escontria chiotilla } & - & -- & $0.0 \pm 0.00 \mathrm{e}$ \\
\hline & 0.5 & -- & $1.2 \pm 0.20 \mathrm{~d}$ \\
\hline & 1.0 & -- & $3.8 \pm 0.66 b$ \\
\hline & 2.0 & -- & $7.6 \pm 0.84 a$ \\
\hline & - & 1.0 & $0.0 \pm 0.00 \mathrm{e}$ \\
\hline & - & 3.0 & $1.7 \pm 0.27 \mathrm{~cd}$ \\
\hline & - & 5.0 & $2.1 \pm 0.34 \mathrm{c}$ \\
\hline \multirow[t]{7}{*}{ Mammillaria carmenae } & - & - & $0.0 \pm 0.00 \mathrm{c}$ \\
\hline & 0.5 & - & $6.2 \pm 0.50 \mathrm{ab}$ \\
\hline & 1.0 & - & $6.4 \pm 0.71 \mathrm{ab}$ \\
\hline & 2.0 & - & $7.7 \pm 0.92 a$ \\
\hline & - & 1.0 & $5.4 \pm 0.42 b$ \\
\hline & - & 3.0 & $5.6 \pm 0.56 b$ \\
\hline & - & 5.0 & $5.5 \pm 0.34 b$ \\
\hline \multirow[t]{7}{*}{ Mammillaria carmenae fo. rubrisprina } & - & - & $0.0 \pm 0.00 \mathrm{c}$ \\
\hline & 0.5 & - & $4.4 \pm 0.57 b$ \\
\hline & 1.0 & - & $6.0 \pm 0.52 a$ \\
\hline & 2.0 & -- & $5.4 \pm 0.63 \mathrm{ab}$ \\
\hline & - & 1.0 & $5.0 \pm 0.51 \mathrm{ab}$ \\
\hline & - & 3.0 & $4.9 \pm 0.28 \mathrm{ab}$ \\
\hline & - & 5.0 & $5.7 \pm 0.34$ a \\
\hline \multirow[t]{7}{*}{ Mammillaria herrerae } & - & - & $0.0 \pm 0.00 \mathrm{e}$ \\
\hline & 0.5 & - & $8.1 \pm 0.85$ a \\
\hline & 1.0 & - & $4.6 \pm 0.23 \mathrm{bc}$ \\
\hline & 2.0 & - & $5.8 \pm 0.56 b$ \\
\hline & - & 1.0 & $3.2 \pm 0.26 \mathrm{~d}$ \\
\hline & - & 3.0 & $3.6 \pm 0.42 \mathrm{~d}$ \\
\hline & - & 5.0 & $4.0 \pm 0.68 \mathrm{~cd}$ \\
\hline \multirow[t]{7}{*}{ Mammillaria theresae } & - & -- & $0.0 \pm 0.00 \mathrm{~d}$ \\
\hline & 0.5 & - & $2.4 \pm 0.42 \mathrm{c}$ \\
\hline & 1.0 & - & $3.5 \pm 0.51 \mathrm{bc}$ \\
\hline & 2.0 & - & $4.2 \pm 0.44 b$ \\
\hline & - & 1.0 & $5.0 \pm 0.86 \mathrm{~b}$ \\
\hline & - & 3.0 & $8.0 \pm 0.77 \mathrm{a}$ \\
\hline & - & 5.0 & $8.2 \pm 0.64 a$ \\
\hline \multirow[t]{7}{*}{ Melocactus curvispinus } & - & - & $0.0 \pm 0.00 \mathrm{~d}$ \\
\hline & 0.5 & - & $3.4 \pm 0.37 \mathrm{c}$ \\
\hline & 1.0 & - & $6.4 \pm 0.46 \mathrm{~b}$ \\
\hline & 2.0 & - & $6.1 \pm 0.50 \mathrm{~b}$ \\
\hline & - & 1.0 & $5.2 \pm 0.50 \mathrm{~b}$ \\
\hline & - & 3.0 & $10.4 \pm 0.47 \mathrm{a}$ \\
\hline & - & 5.0 & $11.8 \pm 0.57 \mathrm{a}$ \\
\hline \multirow[t]{7}{*}{ Polaskia chichipe } & - & - & $0.0 \pm 0.00 \mathrm{e}$ \\
\hline & 0.5 & -- & $1.5 \pm 0.23 \mathrm{~d}$ \\
\hline & 1.0 & -- & $11.5 \pm 0.80 \mathrm{a}$ \\
\hline & 2.0 & - & $7.6 \pm 0.77 b$ \\
\hline & - & 1.0 & $1.3 \pm 0.13 \mathrm{~d}$ \\
\hline & - & 3.0 & $3.9 \pm 0.67 \mathrm{c}$ \\
\hline & - & 5.0 & $5.1 \pm 0.78 \mathrm{C}$ \\
\hline
\end{tabular}

* Este valor se obtuvo dividiendo el número total de brotes generados en el tratamiento entre el número total de explantes sometidos al mismo. Las medias con diferentes letras son significativamente diferentes de acuerdo con la prueba de Tukey-Kramer $(=0.05)$. 

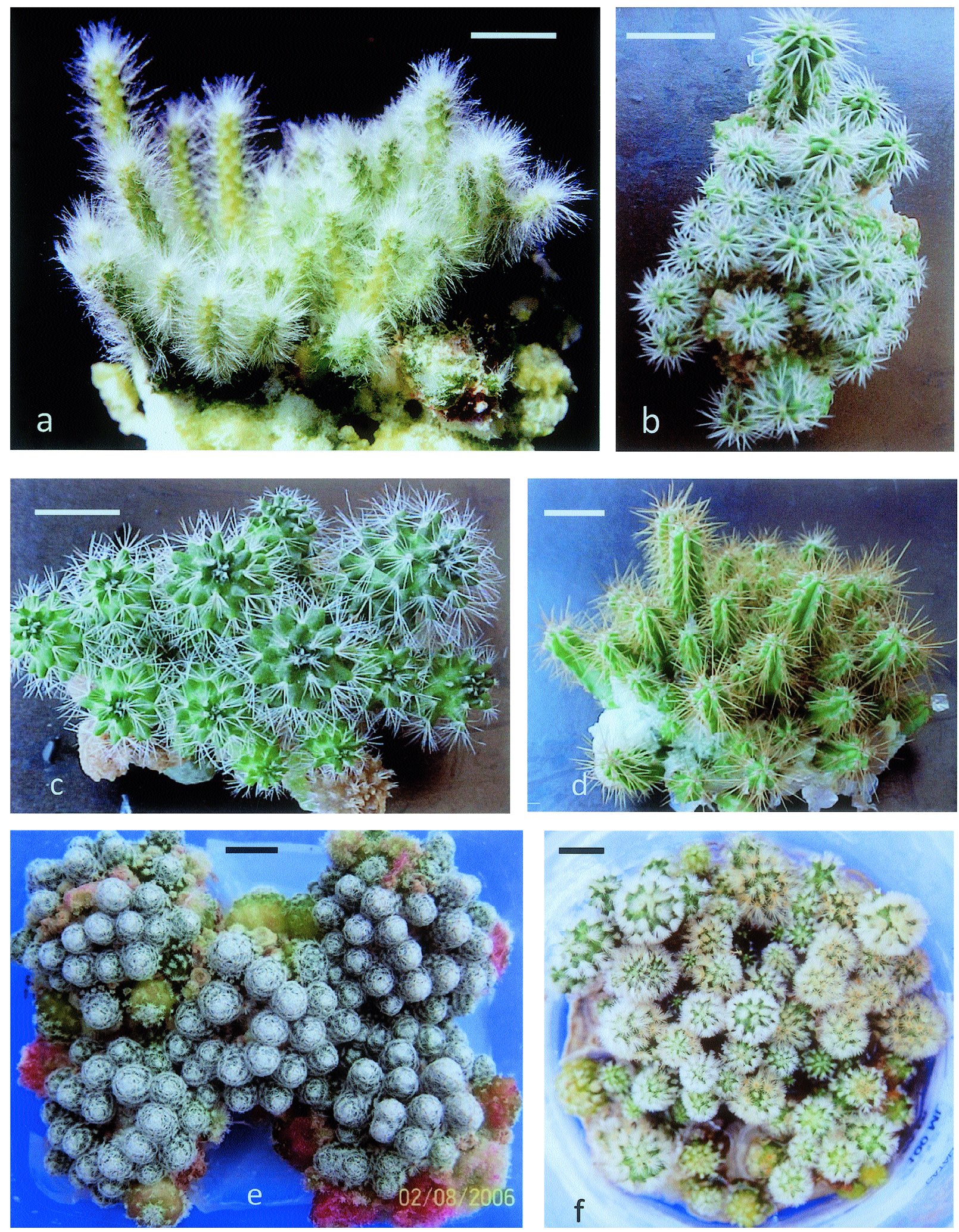

Figura 1. Generación de brotes a través de la activación de areolas en secciones de tallo cultivadas en medio MS. a. Echinocereus sch mollii con $2 \mathrm{mg} \mathrm{L}^{-1}$ de BA. b. Escontria chiotilla con $2 \mathrm{mg} \mathrm{L}^{-1}$ de BA. c. Melocactus curvispinus con $5 \mathrm{mg} \mathrm{L}^{-1}$ de $2 \mathrm{iP}$. d. Polaskia chichi pe con $1 \mathrm{mg} \mathrm{L}^{-1}$ de BA. e. Mammillaria herrerae con $0.5 \mathrm{mg} \mathrm{L}^{-1}$ de BA. f. M. carmenae con $2 \mathrm{mg} \mathrm{L}^{-1}$ de BA. Barra $=10 \mathrm{~mm}$ en todos los casos. 
1992). La multiplicación in vitro de cactáceas también se ha alcanzado a través de otras vías de propagación, como la organogénesis, en Turbinicarpus laui (Mata-Rosas et al., 2001), Selenicereus megalanthus (Pelah et al., 2002), Pelecyphora aselliformis (Santos-Díaz et al., 2003) y Mammillaria albicoma (Wyka et al., 2006). Si bien la eficiencia de estos sistemas es similar o superior a la obtenida a través de la activación de areolas, éstos requieren combinaciones y niveles más altos de reguladores del crecimiento, y además se genera tejido calloso como paso intermedio en el proceso de regeneración. Éstos son factores que pueden favorecer la variación somaclonal (Oliveira et al., 1995), por lo que no son los ideales para la conservación del acervo genético intacto de los materiales silvestres que se están propagando. En este trabajo sólo se observó la generación de tejido calloso en algunos explantes cultiva- dos en las concentraciones más altas de las citocininas probadas ( $2 \mathrm{mg} \mathrm{L}^{-1}$ de BA y $5 \mathrm{mg} \mathrm{L}^{-1}$ de $2 \mathrm{iP}$ ). Sin embargo, aun en estos casos los brotes se generaron a partir de las areolas y no del tejido calloso, por lo que el riesgo de generar variación somaclonal es mínimo. En general, se observó la aparición de un solo brote por areola, por lo que la eficiencia de los tratamientos se relaciona directamente con la proporción de areolas dentro de un explante que son estimuladas a brotar por la citocinina.

El enraizamiento in vitro de los brotes ocurrió con eficiencias de entre 54.8 y $100 \%$ (cuadro 2; figura 2). En cinco especies la mayor eficiencia se observó en el medio con AIB, mientras que dos respondieron mejor en medio con carbón activado, una con AIA y una en medio basal sin auxinas ni carbón activado. Estos resultados coinciden con reportes en Pelecyphora aselliformis y $P$. strobiliformis
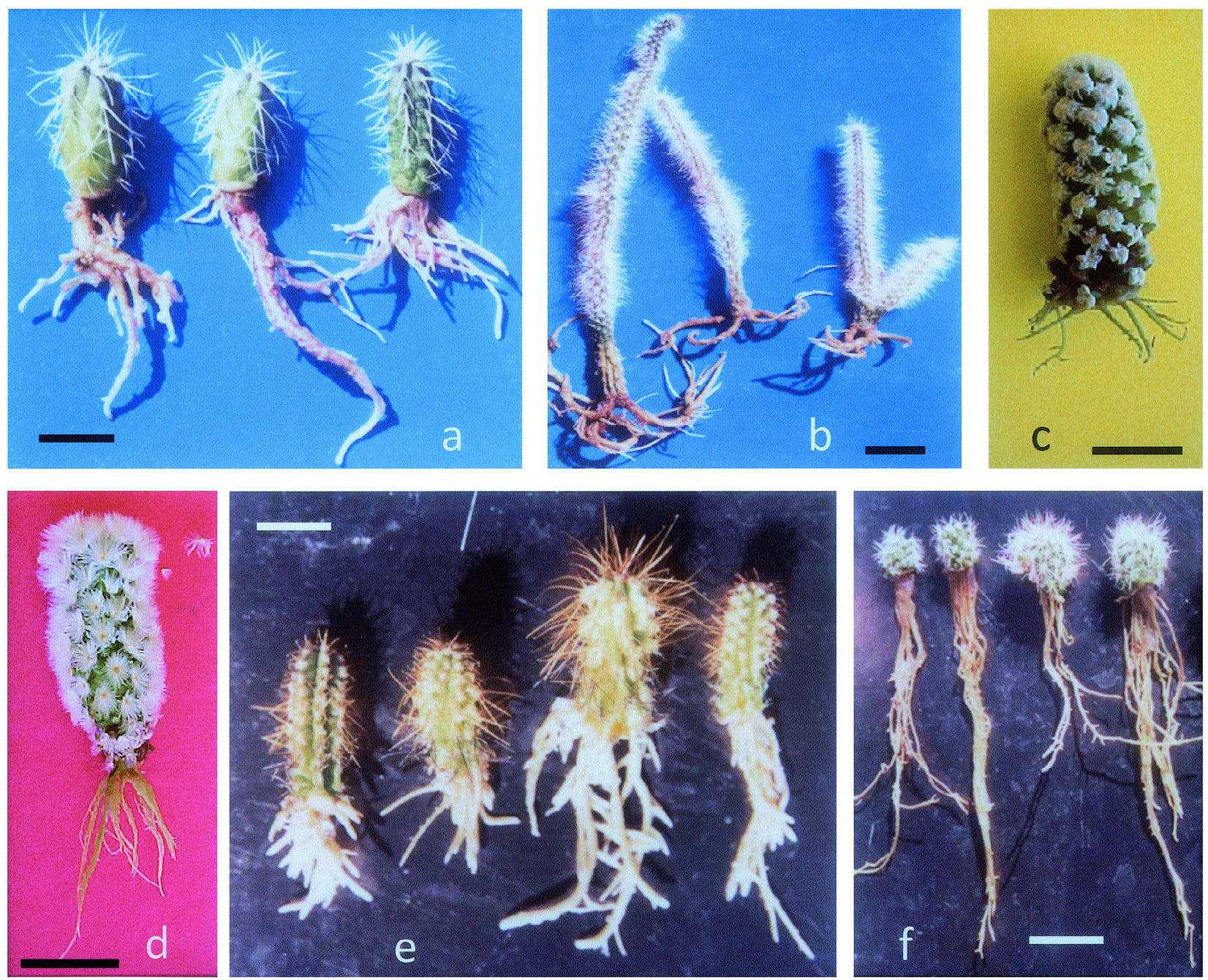

Figura 2. Brotes de seis especies de cactáceas enraizados in vitro: a. Echinocereus knippelianus con $0.5 \mathrm{mg} \mathrm{L^{-1 }}$ de AIB. b. Echinocereus schmollii con $2 \mathrm{~g} \mathrm{~L}^{-1}$ de carbón activado. c. Mamillaria theresae con $0.5 \mathrm{mg} \mathrm{L}^{-1}$ de AIB. d. Mamillaria carmenae MS basal. e. Polaskia chichipe con $0.5 \mathrm{mg} \mathrm{L}^{-1}$ de AIB. f. Melocactus curvispinus con $0.5 \mathrm{mg} \mathrm{L}^{-1} \mathrm{de}$ AIB. Barra $=10 \mathrm{~mm}$ en todos los casos. 
Cuadro 2. Eficiencia de enraizamiento in vitro y supervivencia en suelo.

\begin{tabular}{|c|c|c|c|}
\hline Especie & Mejor tratamiento & $\begin{array}{c}\text { Eficiencia de } \\
\text { enraizamiento (\%)* }\end{array}$ & $\begin{array}{c}\text { Supervivencia en } \\
\text { suelo }(\%)\end{array}$ \\
\hline Echinocereus knippelianus & $0.5 \mathrm{mg} \mathrm{L}^{-1} \mathrm{AIB}$ & 100 & 90 \\
\hline Echinocereus schmollii & $2 \mathrm{~g} \mathrm{~L}^{-1} \mathrm{CA}$ & 72.2 & 70 \\
\hline Escontria chiotilla & $2 \mathrm{~g} \mathrm{~L}^{-1} \mathrm{CA}$ & 100 & 81 \\
\hline Mammillaria carmenae & MS & 66.0 & 92 \\
\hline Mammillaria carmenae fo. rubrisprina & $0.5 \mathrm{mg} \mathrm{L}^{-1} \mathrm{AlA}$ & 67.2 & 98 \\
\hline Mammillaria herrerae & $0.5 \mathrm{mg} \mathrm{L}^{-1} \mathrm{AlB}$ & 59.0 & 49 \\
\hline Mammillaria theresae & $0.5 \mathrm{mg} \mathrm{L}^{-1} \mathrm{AlB}$ & 54.8 & 93 \\
\hline Melocactus curvispinus & $0.5 \mathrm{mg} \mathrm{L}^{-1} \mathrm{AlB}$ & 93.7 & 75 \\
\hline Polaskia chichipe & $0.5 \mathrm{mg} \mathrm{L}^{-1} \mathrm{AIB}$ & 100 & 88 \\
\hline
\end{tabular}

* Sólo se muestra el tratamiento más eficiente en cuanto al porcentaje de enraizamiento que generó. CA = Carbón activado, MS = Medio MS basal.

(Pérez-Molphe-Balch y Dávila-Figueroa, 2002) y en Opuntia (García-Saucedo et al., 2005), cuyo enraizamiento in vitro ocurrió en tratamientos con las auxinas mencionadas. Los porcentajes de supervivencia en suelo de las plantas generadas in vitro fueron satisfactorios en la mayoría de los casos (entre 70 y 98\%). Sólo la especie M. herre rae mostró un porcentaje menor (49\%). En este caso podrían probarse otros substratos para el desarrollo de las plantas, ya que seguramente la mezcla utilizada no fue la más adecuada.

Los métodos de propagación expuestos en este trabajo son más eficientes que cualquiera de los métodos convencionales disponibles para estas especies. Estos sistemas basados en el cultivo in vitro tienen el potencial de generar miles de nuevas plantas en menos de un año partiendo de sólo un fragmento de tejido. En el caso de las especies amenazadas, las plantas generadas in vitro pueden ser utilizadas o comercializadas, disminuyendo así la presión sobre las poblaciones silvestres. En las especies con potencial económico, productoras de frutas, los métodos biotecnológicos pueden ser la base para iniciar programas de mejoramiento y explotación más intensiva de las mismas. Por otro lado, el disponer de metodologías que permiten mantener y propagar in vitro tejidos de estas especies puede facilitar la realización de estudios en áreas como la fitoquímica, la biología celular y la molecular, sin que se haga necesaria para ello la recolección de material silvestre.

\section{Agradecimientos}

A la Universidad Autónoma de Aguascalientes por el apoyo financiero brindado al proyecto. Al Consejo Nacional de Ciencia y Tecnología por la beca para estudios de Maestría otorgada a J.L. Retes-Pruneda.

\section{Literatura citada}

Bravo-Hollis H. y Sánchez-Mejorada H. 1991. Las Cactáceas de México, Vol. III. Universidad Nacional Autónoma de México, México, D.F.

Dávila-Figueroa C., de la Rosa-Carrillo M.L. y Pérez-MolpheBalch E. 2005. In vitro propagation of eight species or subspecies of Turbinicarpus (Cactaceae). In Vitro Cellular and Developmental Biology-Plant 41:540-545.

De Fatima M., Machado P.S. y Prioli A.J. 1996. Micropropagation of Cereus peruvianus Mill. (Cactaceae) by areole activation. In Vitro Cellular and Developmental Biology-Plant 32:199-203.

De Oliveira S.A., da Silva-Machado M.F.P., Prioli A.J. y Aparecida-Mangolin C. 1995. In vitro propagation of Cereus peruvianus Mill. (Cactaceae). In Vitro Cellular and Developmental Biology-Plant 31:47-50.

Elias-Rocha M.A., Santos-Días M.S. y Arredondo-Gómez A. 1998. Propagation of Mammillaria candida (Cactaceae) by tissue culture technique. Haseltonia 6:96-101.

García-Saucedo P.A., Valdez-Morales M., Valverde M.E., CruzHernández A. y Paredes-López, O. 2005. Plant regeneration of three Opuntia genotypes used as human food. Plant Cell, Tissue and Organ Culture 80:215-219.

Hernández H.M. y Godínez-A. H. 1994. Contribución al conocimiento de las cactáceas mexicanas amenazadas. Acta Botanica Mexicana 26:33-52.

Hubstenberger J.F., Clayton P.W. y Phillips G.C. 1992. Micropropagation of cacti (Cactaceae). En: Bajaj Y.P.S. Ed. Biotechnology in Agriculture and Forestry, Vol. 20. High-Tech and Micropropagation IV. pp. 49-68, Springer-Verlag, Berlín y Heidelberg.

Infante R. 1992. In vitro axillary shoot proliferation and somatic embryogenesis of yellow pitaya Mediocactus coccineus (SalmDyck). Plant Cell, Tissue and Organ Culture 31:155-159.

Jordan P.W. y Nobel P.S. 1981. Seedling establishment of Ferocactus acanthodes in re lation to drought. Ecology 62:901906.

Malda G., Suzán H. y Backhaus R. 1999. In vitro culture as a potential method for the conservation of endangered plants 
possessing crassulacean acid metabolism. Scientia Horticulturae 81:71-87.

Martínez-Vázquez O. y Rubluo A. 1989. In vitro mass propagation of the near-extinct Mammillaria san-angelensis SánchezMejorada. The Journal of Horticultural Science 64:99-105.

Mata-Rosas M., Monroy de la Rosa M.A., Moebius-Goldammer K. y Chávez-Ávila V.M. 2001. Micropropagation of Turbinicarpus laui Glass et Foster, an endemic and endangered species. In Vitro Cellular and Developmental Biology-Plant 37:400-404.

Moebius-Goldammer K.G., Mata-Rosas M. y Chávez-Ávila V.M. 2003. Organogenesis and somatic embryogenesis in Ariocarpus kotschoubeyanus (Lem.) K. Schum. (Cactaceae), an endemic and endangered Mexican species. In Vitro Cellular and Developmental Biology-Plant 39:388-393.

Murashige T. y Skoog F. 1962. A revised medium for rapid growth and bio assay with tobacco tissue culture. Physiologia Plantarum 15:473-479.

Ortega-Baes P. y Godínez-Álvarez H. 2006. Global diversity and conservation priorities in the Cactaceae. Biodiversity and Conservation 15:817-827.

Pelah D., Kaushik R.A., Mizrahi Y. y Sitrit Y. 2002. Organogenesis in the vine cactus Selenicereus megalanthus using thidiazuron. Plant Cell, Tissue and Organ Culture 71:8184.

Pérez-Molphe-Balch E. y Dávila-Figueroa C.A. 2002. In vitro propagation of Pelecyphora aselliformis Ehrenberg and P. stro - biliformis Werdermann (Cactaceae). In Vitro Cellular and Developmental Biology-Plant 38:73-78.

Pérez-Molphe-Balch E., Pérez-Reyes M.E., Dávila-Figueroa C.A. y Villalobos-Amador E. 2002. In vitro propagation of three species of columnar cacti from the Sonoran Desert. HortScience 37:693-696.

Rodríguez-Garay B. y Rubluo A. 1992. In vitro morphogenetic responses of the endangered cactus Aztekium ritteri (Boedeker). Cactus and Succulent Journal (U.S.) 64:116-119.

Santos-Díaz M.D.S., Méndez-Ontiveros R., Arredondo-Gómez A. y Santos-Díaz M.D.L. 2003. In vitro organogenesis of Pelecyphora aselliformis Erhenberg (Cactaceae). In Vitro Cellular and Developmental Biology-Plant 39:480-484.

Semarnat [Secretaría del Medio Ambiente y Recursos Naturales]. 2002. Norma Oficial Mexicana NOM-059-ECOL2001, Protección ambiental-Especies nativas de México de flora y fauna silvestres-Categorías de riesgo y especificaciones para su inclusión, exclusión o cambio-Lista de especies en riesgo. Diario Oficial de la Federación. 2a Sección, 6 de marzo de 2002.

Steenbergh W.F. y Lowe C.H. 1969. Critical factors during the first years of life of the saguaro (Cereus giganteus) in the Saguaro National Monument, Arizona. Ecology 50:825-834.

Wyka T., Hamerska M. y Wróblewska M. 2006. Organogenesis of vegetative shoots from in vitro cultured flower buds of Mammillaria albicoma (Cactaceae). Plant Cell, Tissue and Organ Culture 87:27-32. 